\title{
LAS CIUDADES EDUCADORAS ANTE LA SEGREGACIÓN ESCOLAR: CAMINANDO HACIA EL DESARROLLO SOSTENIBLE ${ }^{1}$
}

\author{
Educating Cities Faced with School Segregation: Walking \\ Towards Sustainable Development
}

Pedro Moisés ARAMENDI JÁUREGUI, Itziar REKALDE-RODRÍGUEZ, Esther CRUZ IGLESIAS

Universidad del País Vasco UPV/EHU

pello.aramendi@ehu.eus; itziar.rekalde@ehu.eus; esther.cruz@ebu.eus

https://orcid.org/0000-0003-0869-9357; https://orcid.org/0000-0002-9297-6734;

https://orcid.org/0000-0001-6093-9309

Fecha de recepción: 11/10/2021

Fecha de aceptación: 11/01/2022

Fecha de publicación en línea: 01/03/2022

Cómo citar este artículo: Aramendi Jáuregui, P. M., Rekalde-Rodríguez, I., y Cruz Iglesias, E. (2022). Las ciudades educadoras ante la segregación escolar: caminando hacia el desarrollo sostenible. Teoría de la Educación. Revista Interuniversitaria, 34(2), 209235. https://doi.org/10.14201/teri.27384

RESUMEN

El quehacer fundamental de las Administraciones y de la clase política en general, es mejorar la calidad de vida de la ciudadanía. En lo que se refiere al Objetivo de Desarrollo Sostenible (ODS) número 4, las administraciones deben garantizar una educación inclusiva, equitativa y de calidad y promover oportunidades de aprendizaje

1. Esta investigación ha sido financiada por el Ayuntamiento de Vitoria-Gasteiz y autorizada por la Universidad del País Vasco/Euskal Herriko Unibertsitatea en el marco del programa sobre el Estudio de la Segregación Escolar en Vitoria-Gasteiz (Referencias: 2018.0123 y 2019.0092). 
a lo largo de toda la vida para todos y todas. Uno de los problemas que más incidencia tiene en la igualdad de oportunidades y en el bienestar de los ciudadanos y ciudadanas es la segregación escolar. Este artículo pretende describir el fenómeno de la segregación escolar en 21 ciudades educadoras del Estado español desde la perspectiva de los técnicos y las técnicas municipales, aportando propuestas para abordarlo de manera sostenible. El enfoque utilizado es descriptivo-interpretativo y los instrumentos que se han utilizado para recabar información han sido un cuestionario inicial online y, los documentos escritos (actas) que corroboran los contenidos abordados en el World Café. En cuanto al procedimiento analítico ha consistido en ordenar y dar sentido a la información a través de un análisis categorial. Los resultados apuntan a que las razones explicitadas por los técnicos y las técnicas sobre la segregación escolar están estrechamente relacionadas con factores socioeconómicos, socioculturales y de vivienda (plan urbanístico, residencia familiar, renta y nivel cultural de las familias, proximidad del centro), aspectos étnico-culturales (origen nacional, la tendencia a agruparse por afinidad comunitaria) y la política educativa (trato a las diferentes redes educativas, mapa escolar, funcionamiento de los centros educativos, atención a la diversidad, equidad del sistema educativo...). El abordaje sostenible de este problema exige desarrollar políticas transversales, lograr un alto nivel de coordinación entre las diversas Administraciones (estatal, autonómica y local) y, apelar a la responsabilidad e implicación de la clase política.

Palabras clave: ciudades educadoras; segregación escolar; desarrollo sostenible; exclusión social; igualdad de oportunidades.

\section{ABSTRACT}

The basic task of the administrations and the political class in general is to improve the quality of life of citizens. With regard to Sustainable Development Goal (SDG) 4, administrations must ensure inclusive, equitable and quality education and promote lifelong learning opportunities for all. One of the problems, that most affects to equal opportunities and the well-being of citizens, is school segregation. This article aims to describe the causes and effects of school segregation in the 21 educational cities of Spain from the perspective of municipal technicians and techniques that have participated in this study, offering proposals that redefine the problem in order to tackle it in a sustainable way. The approach used is descriptive-interpretative and the instruments deployed were an initial online questionnaire and written records derived from the implementation of the World Café. The analytical procedure consisted of ordering and making sense of the information through a categorical analysis.. The results addressed that the causes explaining school segregation, defined by the technicians, are closely related to socioeconomic, socio-cultural and housing factors (urban planning, family residence, income, family cultural level, proximity of the school), ethnic-cultural aspects (national origin, the tendency to group together due to community affinity) and education policy (treatment of the different educational networks, distribution of schools, functioning of schools, addressing diversity, equality of the education system, etc.). The sustainable approach to this problem requires the development of transversal policies, a high level of coordination 

CAMINANDO HACIA EL DESARROLLO SOSTENIBLE

between the various administrations (state, regional and local) and the responsibility and involvement of the political class.

Keywords: educating cities; school segregation; sustainable development; social exclusion; equal opportunities.

\section{INTRODUCCIÓN}

La ciudad educadora e inclusiva es aquella en la que cualquier persona puede llevar a cabo un proyecto vital independiente, participando plenamente en la vida política, social y económica con igualdad de oportunidades en relación con el resto de los ciudadanos y las ciudadanas (Ainscow, 2004). El movimiento de ciudades educadoras se inicia en el año 1990, con motivo del Congreso Internacional de Ciudades Educadoras celebrado en Barcelona, donde un grupo de municipios representados por sus gobiernos locales se planteó el objetivo de trabajar conjuntamente en proyectos relacionados con la mejora de la calidad de vida de la ciudadanía. Como nos recuerda Kearns (2015) tanto la corriente de ciudades educadoras como la de ciudades del aprendizaje parten del concepto de aprendizaje a lo largo de la vida.

En concreto la Asociación Internacional de Ciudades Educadoras (AICE) se formalizó en 1994, como estructura permanente de colaboración entre los gobiernos locales, y se comprometió con el desarrollo de la Carta de Ciudades Educadoras (2004). Esta carta se fundamenta en la Declaración Universal de Derechos Humanos (1948); el Pacto Internacional de Derechos Económicos, Sociales y Culturales (1966); la Convención sobre los Derechos de la Infancia (1989); la Declaración Mundial sobre Educación para Todos (1990) y la Declaración Universal sobre la Diversidad Cultural (2001). En el principio 16 de dicha Carta se afirma que los municipios deberán detectar los mecanismos de marginación y desarrollar políticas adecuadas para atender a la ciudadanía, en especial a las personas recién llegadas (inmigrantes o refugiadas) (AICE, 2004). En este sentido, a nivel estatal existe un acuerdo generalizado de que las políticas inclusivas desarrolladas por los municipios son de gran ayuda para afrontar los problemas relacionados con la segregación educativa y social (Bonal, 2018; Martínez y Ferrer, 2018; Murillo y Martínez-Garrido, 2019).

Además, a raíz de la aprobación mundial de la Agenda 2030 y de los Objetivos de Desarrollo Sostenible (ODS), la AICE ha adoptado los ODS como marco de trabajo con los gobiernos locales, especialmente en lo que se refiere al ODS número 4 dedicado a la educación: "Garantizar una educación inclusiva, equitativa y de calidad y promover oportunidades de aprendizaje a lo largo de toda la vida para todos" (ONU, 2015). De hecho, cabe destacar que la fusión que se crea entre los conceptos de ciudad educadora y desarrollo sostenible en la educación se materializa en la realización de proyectos que tengan como objetivo promover el empoderamiento y la sostenibilidad de las comunidades (Dos Santos Figueiredo et al., 2021). 
La Ciudad Educadora es, por tanto, un proyecto político y social que tiene como propósito central la mejora de las condiciones de vida de la ciudadanía (Aldana y Rodríguez, 2018). El ciudadano y la ciudadana tienen derecho a una historia de vida, a un proyecto personal y colectivo digno (Apple, 2015), y para lograrlo la ciudad pensada en perspectiva educadora es un pilar fundamental (Carbonell, 2016).

Uno de los problemas que más incidencia tiene en la igualdad de oportunidades y en la inserción social de los ciudadanos y ciudadanas es la segregación escolar. Según Murillo (2016) se producen situaciones de segregación escolar cuando los y las estudiantes de nivel socioeconómico bajo asisten a instituciones escolares con menos recursos, cuando el alumnado inmigrante extranjero se concentra en centros determinados, o cuando se admite a los y las estudiantes en los centros educativos en función de su rendimiento académico previo. En cualquier caso, la relación entre la elección de centro y la segregación escolar se ha convertido en un fenómeno que acapara la atención de las corporaciones locales en general y de las ciudades educadoras en particular (Cote, 2018; Owens, 2018). Como ponen de manifiesto diferentes autores y autoras, las causas que provocan la segregación escolar y las implicaciones que acarrea en ámbitos diferentes de la vida cotidiana, merecen de estudios exhaustivos y rigurosos para abordarlos con sentido y perspectiva ecológica y sostenible (Ortíz, 2014; Pallarés et al., 2017).

\section{LA SEGREGACIÓN ESCOLAR Y SUS EFECTOS EN LA SOCIEDAD}

El problema de la segregación no sólo afecta al alumnado y sus familias, sino también a la eficacia del sistema educativo en general (Rubia, 2013). Las graves consecuencias se reflejan, por un lado, en una organización escolar ineficiente, con una elevada proporción de alumnado que repite curso o abandona el sistema y, consecuentemente, con un incremento del número de jóvenes sin cualificar y en riesgo de exclusión. Por otro lado, en un descenso a medio plazo de la calidad de vida de la ciudadanía y en la reducción de la cohesión social (Sindic de Greuges, 2016).

El concepto de segregación escolar es el resultado de las desviaciones que se dan entre la composición de las escuelas y el entorno en el que se encuentran ubicadas (Murillo y Martínez-Garrido, 2019). Es un problema poco visible, sibilino, que se ha ido agravando en los últimos años y que, en la actualidad, constituye una prioridad en la política educativa española. De hecho, el Estado español es el sexto país europeo con mayor segregación en su sistema educativo, sufriendo un aumento del 13,4\% en la última década (Martínez y Ferrer, 2018). Además de los desequilibrios sociales y la falta de equidad educativa que este problema genera, Murillo, Martínez-Garrido y Belavi (2017) analizan las implicaciones que tienen la segregación escolar en el fomento de la interculturalidad y las interacciones sociales. La segregación escolar provoca que el alumnado inmigrante se concentre en unas escuelas determinadas, generando guetos $y$, negando la posibilidad de que el centro sea un espacio de encuentro e interrelación entre culturas (Bellei, 2013; Donato y Hanson, 2019; Rosiek, 2019). 
Los procesos de discriminación producidos en el interior de los centros educativos (segregación interna) también son preocupantes (Macartney y Singleton, 2017) porque como afirma Pàmies (2013), algunos grupos de estudiantes, generalmente de rendimiento académico bajo, tienen acceso a currículos y experiencias educativas precarias. Compartir la misma escuela no supone para los y las estudiantes tener acceso a experiencias curriculares, expectativas académicas y relaciones sociales similares (Sleeter, 2018). Al margen de la incidencia de la procedencia familiar, las características agregadas del alumnado tienen un efecto adicional sobre el rendimiento académico individual, llamado efecto composición (Alegre, 2008; Benito y González, 2013).

En relación con los factores vinculados con la segregación escolar, Rossetti (2014) identifica algunas causas que la originan: las tendencias demográficas y la segregación residencial, la elección de centro por parte de las familias (motivada por factores étnicos y sociales) y, finalmente, la selección del estudiantado por parte de los colegios. Además de estas causas, la segregación escolar se hace evidente en la selección institucional del alumnado entre itinerarios académicos y profesionales. En los sistemas dónde la selección se hace a edades más tempranas, la desigualdad entre los itinerarios aumenta y la segregación escolar es mayor, puesto que las y los estudiantes viven experiencias escolares diferentes durante más tiempo (Valiente, 2008). A todo esto, hay que añadir que, ciertas normas de admisión del alumnado en los centros educativos (tales como desempeño escolar, creencias o religión) también se asocian con los antecedentes sociales o étnicos del propio alumnado (Billingham, 2019). Y por si fuera poco, la privatización de la educación además promueve más desequilibrios sociales y mayor segregación escolar (Bonal, 2018; Bonal y Verger, 2016). Es por todo ello que, cada vez más estudios cuestionan decididamente los principios actuales de la selección de centro en el sistema educativo español, ya que agrava aún más el problema de la segregación en la población estudiantil (Hernández y Raczynski, 2015). Las ciudades educadoras reivindican el protagonismo de los municipios como contextos de actuación para prevenir e intervenir en los procesos de exclusión educativa y social (Jimenez, 2017), dado que las políticas públicas deben afrontar las causas que obstaculizan la inclusión social y la igualdad de oportunidades de la ciudadanía, especialmente, de las personas pertenecientes a los colectivos más vulnerables (Erickson y Highsmith, 2018).

El objetivo general de esta investigación reside en identificar y describir los elementos que inciden en el fenómeno de la segregación escolar en 21 ciudades educadoras del Estado español, desde la perspectiva de los técnicos y las técnicas municipales, aportando, a la vez, propuestas de mejora basadas en la sostenibilidad. Los objetivos específicos que persigue este estudio son:

- Conocer la disponibilidad de datos e informaciones que poseen estas ciudades para conocer e intervenir sobre el fenómeno de la segregación escolar.

- Identificar las causas relacionadas con el fenómeno de la segregación escolar desde el punto de vista de los técnicos y las técnicas de las ciudades educadoras participantes en el estudio. 
- Describir los efectos de la segregación escolar en la vida cotidiana de las ciudades participantes.

- Dar a conocer las intervenciones que desarrollan las ciudades educadoras a la hora de paliar los efectos de la segregación escolar.

\section{MÉTODO}

En coherencia con el marco teórico y los objetivos del estudio, se ha optado por un enfoque descriptivo-interpretativo. Este enfoque se considera idóneo para analizar las opiniones de las personas investigadas, de tal manera que quienes investigan comprendan adecuadamente sus puntos de vista (Janesick, 2000). El estudio se ha articulado de manera cualitativa (Taylor y Bogdan, 1994) al objeto de comprender y profundizar en las opiniones y valoraciones realizadas por los y las participantes en torno a la segregación escolar en las ciudades educadoras y, posteriormente, realizar propuestas que ayuden a paliar este complejo problema (Grundy, 1991; Flick, 2011).

\subsection{Participantes}

Las personas colaboradoras han sido 21 técnicos y técnicas municipales (representantes de cada municipio) que han participado de manera voluntaria en este estudio. En la Figura 1 se recogen, por orden alfabético, las 21 ciudades educadoras que han participado incluyendo, la comunidad autónoma a la que pertenecen y el tipo de localidad (ciudad pequeña, mediana, mediana integrada en área metropolitana, y grande) (Jordá, 2020).

Como puede apreciarse en la Figura 1 la Comunidad Autónoma con más personal técnico que ha participado en el estudio ha sido Cataluña, seguido del País Vasco y Madrid.

Como se aprecia en la Figura 2 el 48 \% de la muestra pertenece a ciudades medianas integradas en áreas metropolitanas. Son los municipios que se encuentran inmersos en el área metropolitana de una gran ciudad. Estas ciudades, si bien a veces pueden tener una dimensión importante adolecen de muchos servicios porque éstos son proporcionados por la gran ciudad a cuya área metropolitana pertenecen. Es decir, que sus habitantes desarrollan buena parte de sus actividades diarias en la capital del área metropolitana. Como señala Jordá (2020) son ciudades que, por un lado, pueden beneficiarse de la capacidad de atracción de la capital a la que se encuentran adosadas, mientras que por el otro, sufren la tendencia a que sea la capital quien absorba los servicios de educación, sanidad, cultura, justicia, tecnología... y, mientras se expulsa activos menos interesantes (vertederos de residuos, plantas depuradoras de aguas,...) a su extrarradio. El $38 \%$ de la muestra pertenece a ciudades intermedias, alejadas de una gran ciudad pero que son el centro de referencia para un amplio territorio (ciudades pequeñas, pueblos y zonas rurales) al que proporcionan todo tipo de servicios 
PEDRO MOISÉS ARAMENDI JÁUREGUI, ITZIAR REKALDE-RODRÍGUEZ, Y ESTHER CRUZ IGLESIAS

LAS CIUDADES EDUCADORAS ANTE LA SEGREGACIÓN ESCOLAR:

CAMINANDO HACIA EL DESARROLLO SOSTENIBLE

\section{FIGURA 1}

\section{CIUDADES EDUCADORAS PARTICIPANTES EN EL ESTUDIO}

C1. Alcoi (Comunidad Valenciana) 57.646 habitantes, ciudad intermedia

C2. Barakaldo (País Vasco) 100.435 habitantes, mediana integrada en área metropolitana

C3. Barcelona (Cataluña) 1,7 millones de habitantes, grande

C4. Bilbao (País Vasco) 346.843 habitantes, ciudad mediana

C5. Ciudad Real (Castilla La Mancha) 75.835 habitantes, ciudad mediana

C6. Girona (Cataluña) 99.494 habitantes, ciudad mediana

C7. Getafe (Comunidad de Madrid) 183.374 habitantes, mediana integrada en área metropolitana

C8. Lleida (Cataluña) 138.956 habitantes, ciudad mediana

C9. Mataró (Cataluña) 129.680 habitantes, mediana integrada en área metropolitana

C10. Sant Boi (Cataluña) 83.996 habitantes, mediana integrada en área metropolitana

C11. Terrassa (Cataluña) 217.756habitantes, mediana integrada en área metropolitana

C12. Móstoles (Comunidad de Madrid) 206.589 habitantes, mediana integrada en área metropolitana

C13. Rivas Vaciamadrid (Comunidad de Madrid) 88.150 habitantes, mediana integrada en área metropolitana

C14. Sabadell (Cataluña) 208.438 habitantes, mediana integrada en área metropolitana

C15. Valencia (Comunidad Valenciana) 794.518 habitantes, ciudad intermedia

C16. Sant Feliu de LLobregat (Cataluña) 44.860 habitantes, ciudad pequeña

C17. Tarragona (Cataluña) 134.515 habitantes, ciudad mediana

C18. Ibi (Comunidad Valenciana) 23.489 habitantes, ciudad pequeña

C19. Granollers (Cataluña) 60.655 habitantes, mediana integrada en área metropolitana

C20. Prat de Llobregat (Cataluña) 62.637 habitantes, mediana integrada en área metropolitana

C21. Vitoria-Gasteiz (País Vasco) 255.042 habitantes, ciudad mediana

Fuente: Elaboración propia

FiguRA 2

TIPOS DE CIUDADES QUE HAN PARTICIPADO EN EL ESTUDIO

\section{Tipos de ciudades del estudio}

- Pequeña $\quad$ Mediana integrada en área metropolitana $\square$ Intermedia $\square$ Grande

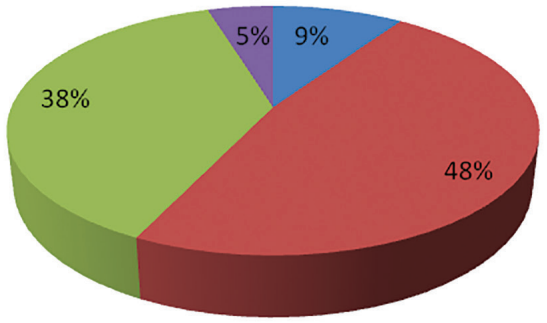

Fuente: Elaboración propia 
(educación superior, sanidad, ocio, comercio, empleo...). El $9 \%$ de la muestra pertenece a ciudades pequeñas que en muchos casos no disponen de los recursos y servicios de las grandes ciudades y, por último, el $5 \%$ pertenece a ciudades grandes que tienen aproximadamente 1 millón de habitantes.

\subsection{Instrumentos}

Se han utilizado principalmente dos instrumentos para la recogida de información; por un lado, un cuestionario inicial y, por otro, las actas escritas que provienen del despliegue de la utilización de la técnica participativa conocida como World Café. Ambos instrumentos se han llevado a cabo con las y los 21 representantes municipales de las ciudades educadoras participantes en el estudio.

Respecto al cuestionario se ha utilizado para obtener información de manera ágil y rápida (Casas et al., 2003). En este caso para conocer la tendencia en la opinión de las y los técnicos de las ciudades educadoras respecto a la segregación escolar, y no con el propósito de cuantificar sus respuestas ni establecer relaciones causales. Este instrumento está compuesto por 6 preguntas complejas que son: 1) ¿Cuáles son las causas y los efectos de la segregación escolar?; 2) En una ciudad educadora ¿Desde qué valores se ha de abordar la intervención ante la segregación escolar?; 3) ¿Cuál es el ámbito competencial de tu municipio ante la segregación escolar?; 4) Según tu opinión ¿Qué objetivos debe perseguir la intervención de una ciudad educadora ante la segregación escolar?; 5) ¿Qué medidas pueden desarrollar los municipios para paliar los efectos negativos de la segregación escolar?, y 6) Según tu opinión ¿¿Desde qué perspectiva se debe intervenir (intervención comunitaria, intervención específica con el centro escolar...)? En cada una de estas preguntas la persona participante escribía su opinión al respecto, recogiendo, por tanto, enunciados basados en las voces y convicciones de los y las participantes.

Los cuestionarios se enviaron y contestaron online.

En cuanto a las actas generadas en la dinámica participativa del World Café, se ha llevado a cabo un análisis documental (Bisquerra, 2012), de tal manera que se ha sistematizado y organizado para ofrecer diferentes enfoques sobre el tema objeto de estudio (Rodríguez et al., 1999).

En cuanto a la técnica participativa de la que proviene la información, señalar que se llevó a cabo una reunión conjunta entre todas las y los técnicos municipales, por un lado, y los miembros del equipo de investigación por otro, en la que se presentaron las tendencias en las respuestas obtenidas a través del cuestionario y se subrayaron los aspectos que todavía necesitaban de un mayor contenido para ofrecer una descripción completa y ajustada de la situación. Para ello se puso en marcha el World Café con el propósito de impulsar la inteligencia colectiva de todas las personas participantes. Esta técnica consiste en un proceso organizacional de trabajo en equipo basado en el diálogo y el aprendizaje cooperativo de forma que las respuestas se van construyendo entre todos los participantes. Permite que un grupo de personas reflexione sobre preguntas 
importantes para generar acuerdos e itinerarios de actuación innovadores (Brown y Isaacs, 2006). Se organizaron 3 mesas de trabajo y en cada una de ellas se plantearon los temas que necesitaban de una mayor indagación, a saber: Mesa 1, causas de la segregación escolar; Mesa 2, efectos de este fenómeno, y Mesa 3, intervenciones de los municipios participantes. Las y los técnicos municipales se dividieron en los 3 grupos, cada uno de los cuáles conversó durante 30 minutos el tema correspondiente a su mesa. En cada grupo, una persona del equipo de investigación actuó de moderador/a y otro de secretario/a. Al finalizar el tiempo, cada subgrupo rotó de posición hasta que los subgrupos participaron en todas las mesas. Cada secretario/a tomó acta de los comentarios que se compartieron durante la sesión de trabajo que son las que han sido objeto de análisis.

\subsection{Diseño de la investigación}

El diseño de la investigación ha consistido en la descripción detallada del trabajo de campo realizado. El itinerario, que a continuación se recoge (Figura 3), se ha ido construyendo y reconstruyendo a medida que avanzaba la investigación a partir de una guía previa, que representaba una planificación provisional del trabajo. Subrayemos el carácter provisional y el sentido cíclico y en espiral de las fases en las que se ha intentado desarrollar el estudio. Dicho itinerario recoge las fases diferenciadas, los instrumentos de investigación, la fuente utilizada, la dinámica analítica, la persona responsable de la elaboración y el proceso de validación y comunicación de los resultados.

Tal y como se refleja en la Figura 3 el equipo de investigación elaboró las conclusiones preliminares que fueron enviadas a las y los técnicos representantes de las ciudades educadoras para que las contrastaran, matizaran, y añadieran aquello que consideraran oportuno antes de construir el documento final consensuado.

\subsection{Procedimiento analítico}

El procedimiento analítico se ha desarrollado de forma concomitante al trabajo de campo (Goetz y Lecompte, 1988). En éste el análisis de la información obtenida ha representado un proceso, básicamente inductivo, dinámico y sistemático que ha requerido identificar, seleccionar, categorizar, comparar e interpretar el mensaje de la información obtenida a través del cuestionario, las actas del World Café y el contraste y matización del documento final consensuado facilitado por las y los técnicos municipales de las ciudades educadoras participantes (Coffey y Atkinson, 2003). En todo este proceso la comprensión del fenómeno de la segregación escolar en las ciudades educadoras ha interactuado constantemente (Lukas y Santiago, 2016; Taylor y Bogdan, 1994). Las categorías resultantes han sido las que se recogen en la Tabla 1, y recogen la opinión de los técnicos y las técnicas municipales sobre cada una de las categorías. 
FIGURA 3

DISEÑO DE LA INVESTIGACIÓN

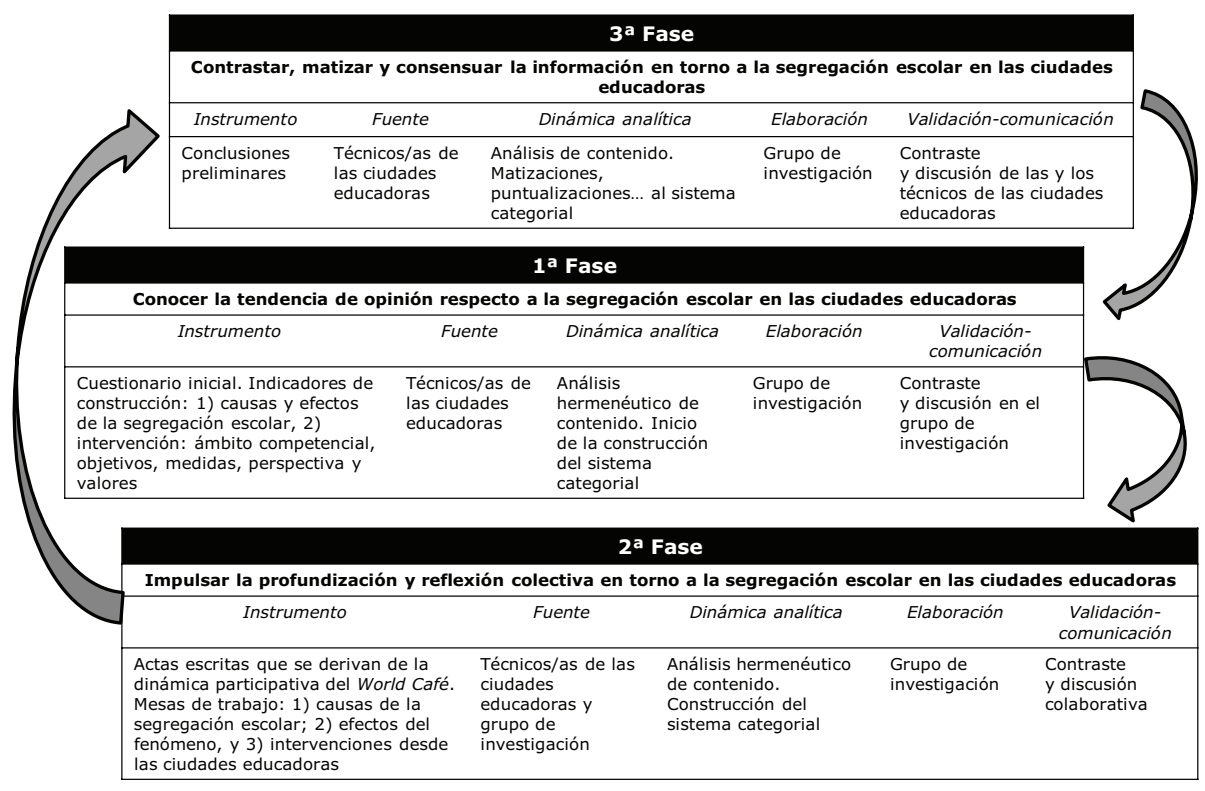

Fuente: Elaboración propia

TABLA 1

SISTEMA CATEGORIAL

\section{Sistema categorial}

\begin{tabular}{ll}
\hline Categoría & Subcategoría \\
\hline Causas de la segregación escolar en la vida de las ciudades & $\begin{array}{c}\text { De tipo social } \\
\text { De tipo familiar } \\
\text { Efectos de la segregación escolar en la vida de las ciudades }\end{array}$ \\
\hline Disponibilidad de información para abordar la segregación escolar & \\
\hline \multirow{2}{*}{ Intervenciones de ciudades educadoras ante la segregación escolar } & Ámbito educativo \\
\cline { 2 - 2 } & Ámbito familiar \\
\hline
\end{tabular}

Fuente: Elaboración propia

\subsection{Cuestiones éticas}

Se han codificado los datos personales para preservar la privacidad y el anonimato, y se ha defendido y velado con respeto en todo momento la información proporcionada por las personas participantes a través de los diferentes instrumentos utilizados, tal y como señala el Comité de Ética para las Investigaciones relacionadas 
con los Seres Humanos de la Universidad del País Vasco/Euskal Herriko Unibertsitatea (CEISH, 2020).

\section{Resultados}

Los resultados se presentan siguiendo el sistema categorial resultante del proceso de análisis que nos permite acercarnos a las causas y los efectos de la segregación escolar; la disponibilidad de información de que disponen las y los técnicos municipales para llevar a cabo su trabajo, y las intervenciones que se desarrollan desde las ciudades educadoras para paliar esta segregación.

\subsection{Las causas y los efectos de la segregación escolar en la vida de las ciudades}

Las personas informantes nos muestran, por orden descendente, cuáles son las causas que según ellos y ellas más se recalcan en la segregación escolar: nivel socioeconómico de las familias (85,7 \%), planificación urbanística de las ciudades $(76,1 \%)$, origen étnico-cultural $(71,4 \%)$, política educativa desarrollada por la Administración (47,6\%), diferencias entre redes educativas (42,8\%), creencia religiosa $(28,5 \%)$, exclusión de determinados centros por rendimiento académico $(28,5$ $\%)$, origen de los estudiantes (19\%), ideología de los políticos (14,2\%), ubicación geográfica de las personas en la ciudad $(9,5 \%)$ y lengua materna $(4,7 \%)$.

En cuanto a los efectos de la segregación escolar en la vida cotidiana de las ciudades, los y las representantes de las ciudades participantes analizan los efectos de la segregación escolar (véase Tabla 2), y según su opinión, las repercusiones son múltiples, variadas y complejas.

En relación a los efectos sociales de la segregación escolar, las ciudades participantes en el estudio afirman que este problema influye poderosamente en la igualdad de oportunidades (C21 y C1), repercute en las interacciones sociales entre diferentes colectivos (C10) y, en consecuencia, en la convivencia ciudadana (C2). Se produce también una diferenciación entre clases sociales a la hora de seleccionar centro. Las clases altas eligen centros escolares donde prácticamente no existe inmigración (centros blancos), produciéndose situaciones de aislamiento social y guetización (C8 y C9). Así mismo, la política de vivienda puede generar desequilibrios, así como la planificación urbanística de las ciudades puede convertirse en la antesala de la segregación escolar y social (C11).

Respecto a las repercusiones en la institución familiar, se debe subrayar, en primer lugar, los diferentes criterios de selección de centro que tienen las familias de diversas clases sociales. La clase media-alta prioriza las características del proyecto educativo, los resultados académicos y la composición social (C6 y C10). Sin embargo, las familias de clase baja seleccionan su centro educativo en función de la proximidad e incluso intentan reagrupar a sus hijos e hijas en la misma escuela 
TABLA 2

EFectos de la Segregación Escolar (REsumen)

\begin{tabular}{|c|c|c|c|}
\hline Ciudad & De tipo social & De tipo familiar & De tipo educativo \\
\hline C1 & $\begin{array}{l}\text { - Falta de cohesión } \\
\text { social, no hay in- } \\
\text { tegración social, } \\
\text { provoca guetos. }\end{array}$ & $\begin{array}{l}\text { - Retirada de los hijos/ } \\
\text { as de las familias } \\
\text { autóctonas. } \\
\text { - Familias de altas ex- } \\
\text { pectativas huyen del } \\
\text { centro. }\end{array}$ & $\begin{array}{l}\text { - Existe un desequilibrio } \\
\text { entre red concertada } \\
\text { y pública. Sólo hay } 4 \\
\text { escuelas públicas y } 9 \text { con- } \\
\text { certadas (de la iglesia). }\end{array}$ \\
\hline $\mathrm{C} 2$ & $\begin{array}{l}\text { - Se fomentan guetos: } \\
\text { la convivencia se } \\
\text { limita a sus iguales. }\end{array}$ & $\begin{array}{l}\text { - Reagrupación familiar } \\
\text { en centros por soli- } \\
\text { citud expresa de la } \\
\text { familia. }\end{array}$ & $\begin{array}{l}\text { - El nivel académico del } \\
\text { alumnado de centros en } \\
\text { los que existe un elevado } \\
\text { porcentaje de inmigrantes } \\
\text { es más bajo. }\end{array}$ \\
\hline C5 & $\begin{array}{l}\text { - La cohesión social y } \\
\text { la convivencia entre } \\
\text { población autóctona } \\
\text { e inmigrante. } \\
\text { - Existe segregación } \\
\text { urbanística. }\end{array}$ & $\begin{array}{l}\text { - Las familias con ori- } \\
\text { gen inmigrante y con } \\
\text { situación económica } \\
\text { precaria participan } \\
\text { menos en el centro. }\end{array}$ & $\begin{array}{l}\text { - Se favorece la segregación } \\
\text { en los centros concertados } \\
\text { a través de criterios como } \\
\text { la ad scripción única. } \\
\text { - Los inmigrantes ralentizan } \\
\text { el aprendizaje (creencia). }\end{array}$ \\
\hline C6 & $\begin{array}{l}\text { - Segregación urba- } \\
\text { nística. }\end{array}$ & $\begin{array}{l}\text { - Las familias priorizan } \\
\text { la proximidad, el } \\
\text { proyecto educativo } \\
\text { innovador del centro } \\
\text { y la composición } \\
\text { social del alumnado } \\
\text { del centro. }\end{array}$ & $\begin{array}{l}\text { - El abandono escolarpre- } \\
\text { maturo y el absentismo. } \\
\text { - La disponibilidad de } \\
\text { vacantes y la atención } \\
\text { de la matrículaviva se- } \\
\text { concentran en centros } \\
\text { segregados. }\end{array}$ \\
\hline C7 & $\begin{array}{l}\text { - Aislamiento social y } \\
\text { "guetización" } \\
\text { - Problemas de la } \\
\text { inclusión de los } \\
\text { alumnos/as y fami- } \\
\text { lias del extranjero. }\end{array}$ & $\begin{array}{l}\text { - No contar con fami- } \\
\text { lias autóctonas, que } \\
\text { puedan transmitir los } \\
\text { valores educativos y } \\
\text { culturales que com- } \\
\text { partimos, supone un } \\
\text { hándicap. Sin esta } \\
\text { interacción la escuela } \\
\text { se empobrece. }\end{array}$ & $\begin{array}{l}\text { - La segregación en la } \\
\text { ciudad C7 no obedece a } \\
\text { una lógica simplemente } \\
\text { público-privada. Existe se- } \\
\text { gregación en las escuelas } \\
\text { públicas y en las concer- } \\
\text { tadas (en ambas). }\end{array}$ \\
\hline C8 & $\begin{array}{l}\text { - Algunas familias } \\
\text { se creen parte del } \\
\text { "grupo de poder" } \\
\text { (prestigio). }\end{array}$ & $\begin{array}{l}\text { - Los empresarios/ } \\
\text { as escolarizan a sus } \\
\text { hijos/as en la concer- } \\
\text { tada }\end{array}$ & $\begin{array}{l}\text { - Los centros bilingües con- } \\
\text { centran estudiantes mayor } \\
\text { rendimiento académico y } \\
\text { con mayor poder adqui- } \\
\text { sitivo }\end{array}$ \\
\hline
\end{tabular}

(continúa) 
PEDRO MOISÉS ARAMENDI JÁUREGUI, ITZIAR REKALDE-RODRÍGUEZ, Y ESTHER CRUZ IGLESIAS

LAS CIUDADES EDUCADORAS ANTE LA SEGREGACIÓN ESCOLAR:

CAMINANDO HACIA EL DESARROLLO SOSTENIBLE

\begin{tabular}{|c|c|c|c|}
\hline Ciudad & De tipo social & De tipo familiar & De tipo educativo \\
\hline C9 & $\begin{array}{l}\text { - Centros blancos: } \\
\text { escolarización sin } \\
\text { compartir aula con } \\
\text { otras clases sociales }\end{array}$ & $\begin{array}{l}\text { - Familias autóctonas } \\
\text { con más expectativas } \\
\text { (fuga a otros centros). }\end{array}$ & $\begin{array}{l}\text { - Centros públicos utilizan } \\
\text { la innovación como factor } \\
\text { llamada (bilingüismo...). }\end{array}$ \\
\hline C10 & $\begin{array}{l}\text { - Estructuras e inte- } \\
\text { racciones sociales. } \\
\text { - Afecta en todos los } \\
\text { ámbitos sociales. }\end{array}$ & $\begin{array}{l}\text { - El principal factor de } \\
\text { elección de centro de } \\
\text { familias: composición } \\
\text { social, proyecto edu- } \\
\text { cativo, instalaciones, } \\
\text { servicios que ofrece... }\end{array}$ & $\begin{array}{l}\text { - Condiciones para la } \\
\text { inclusión. Menos oportu- } \\
\text { nidades de interacción de } \\
\text { los segregados. } \\
\text { - El número de centros } \\
\text { privados ha crecido (pri- } \\
\text { vatización). }\end{array}$ \\
\hline C11 & $\begin{array}{l}\text { - Efecto de arrastre: } \\
\text { de la segregación } \\
\text { residencial a la se- } \\
\text { gregación escolar. }\end{array}$ & $\begin{array}{l}\text { - Medidas de la libre } \\
\text { elección de castro } \\
\text { (zona única) segregan } \\
\text { a familias. }\end{array}$ & $\begin{array}{l}\text { - Dificulta la efectividad de } \\
\text { las políticas educativas y } \\
\text { los Servicios Sociales. La } \\
\text { segregación promueve la } \\
\text { exclusión. }\end{array}$ \\
\hline $\mathrm{C} 13$ & $\begin{array}{l}\text { - Cohesión social, } \\
\text { estructuras e inte- } \\
\text { racciones sociales. }\end{array}$ & $\begin{array}{l}\text { - La cantidad de } \\
\text { actividades comple- } \\
\text { mentarias condiciona } \\
\text { el presupuesto fami- } \\
\text { liar. }\end{array}$ & $\begin{array}{l}\text { - Los centros que segregan } \\
\text { optan por el bilingüismo } \\
\text { para atraer a mejor alum- } \\
\text { nado (segregación por } \\
\text { bílingüismo). }\end{array}$ \\
\hline C14 & $\begin{array}{l}\text { - Estigmatizan a } \\
\text { alumnos/as, familias, } \\
\text { centros educativos y } \\
\text { territorios. }\end{array}$ & $\begin{array}{l}\text { - No escolarizan a sus } \\
\text { hijas/os por tratarse } \\
\text { de una etapa que no } \\
\text { es obligatoria (etapa } \\
\text { 0-3 años). }\end{array}$ & $\begin{array}{l}\text { - Desde este convencimien- } \\
\text { to, la segregación escolar } \\
\text { (externae interna) es uno } \\
\text { de los principales retos. }\end{array}$ \\
\hline C19 & $\begin{array}{l}\text { - Problemas de convi- } \\
\text { vencia. }\end{array}$ & $\begin{array}{l}\text { - Efecto buida de las } \\
\text { familias. }\end{array}$ & $\begin{array}{l}\text { - Segregación natural: mapa } \\
\text { escolar determinado por } \\
\text { lugar de residencia. La } \\
\text { normativa de la Adminis- } \\
\text { tración segrega. }\end{array}$ \\
\hline C21 & $\begin{array}{l}\text { - Falta de cohesión } \\
\text { social. }\end{array}$ & $\begin{array}{l}\text { - Reagrupación de los } \\
\text { hijos/es en el mismo } \\
\text { centro educativo. }\end{array}$ & $\begin{array}{l}\text { - Alumnado agrupado en } \\
\text { función de: planificación } \\
\text { urbanística, mapa escolar, } \\
\text { la creencia religiosa, ori- } \\
\text { gen étnico-cultural, red } \\
\text { educativa, rendimiento. } \\
\text { ISEC... }\end{array}$ \\
\hline
\end{tabular}


incrementando, de esta manera, la concentración de estudiantes de las mismas características. Esta tendencia genera el efecto retirada o buida de las familias más acomodadas hacia otro tipo de escuelas (C1 y C9). Según los informantes, a la hora de seleccionar centro, la creación de zonas únicas por parte de la Administración Educativa alimenta (de forma consciente o involuntaria) los fenómenos de segregación escolar y de aislamiento social (C11). Los representantes de las ciudades también destacan la discriminación que se produce en el acceso a actividades extraescolares, complementarias y la escasa participación de niños y niñas de clase socioeconómica baja en el primer ciclo de Educación Infantil (0-3 años). La falta de recursos económicos de algunas familias limita su participación en servicios educativos de este tipo (C14 y C13).

En cuanto a los efectos educativos, se detectan repercusiones importantes. En primer lugar, existe la creencia de que los centros con gran concentración de estudiantes inmigrantes ralentizan el rendimiento de los nacionales (C5). Es decir, se promociona deliberadamente la idea de que los niveles académicos de estos centros son más bajos (C2 y C21) y que existe más absentismo y abandono escolar (C6). Algunos centros públicos utilizan el factor innovación para atraer a las familias, mientras que los colegios privados concertados utilizan el factor bilingüismo o trilingüismo para que las familias matriculen a sus hijos e hijas en sus centros (C8 y C13). Finalmente, se constata que la segregación tiene efectos e implicaciones en los Servicios Sociales de Base, haciendo que la segregación escolar alimente la exclusión social (C11).

\subsection{Disponibilidad de la información que manejan las técnicas y los técnicos muni- cipales para trabajar en torno a la segregación escolar}

En cuanto a la disponibilidad de la información que manejan los técnicos y las técnicas municipales para trabajar en torno a la segregación escolar (véase Tabla 3), y según su punto de vista, la mayoría de las ciudades no tienen información de datos concretos sobre la misma.

Los municipios comprenden la magnitud del problema, pero no poseen la información necesaria para realizar intervenciones basadas en diagnósticos certeros. Solamente tres capitales de provincia y de comunidad autónoma (C3, C15 y C21) tienen un convenio con sus respectivos Departamentos Autonómicos de Educación.

La amplia mayoría de las ciudades realiza estimaciones mediante datos relacionados con el número de matrículas por centro y redes, los porcentajes de inmigración, matrícula viva, vacantes, subvenciones y ayudas proporcionadas por los municipios (becas, libros de texto...), número de alumnado con necesidades educativas de apoyo, absentismo y abandono escolar y datos socioeconómicos, y urbanísticos de los barrios de la ciudad.

Las capitales de provincia que obtienen datos sobre la segregación escolar gozan de algún privilegio en esta cuestión. Los Departamentos de Educación de 
TABLA 3

INFORMACIÓN DISPONIBLE EN LOS MUNICIPIOS

SOBRE LA SEGREGACIÓN ESCOLAR (RESUMEN)

\begin{tabular}{|c|c|c|}
\hline Ciudad & $\begin{array}{l}\text { En tu municipio. ¿se } \\
\text { recogen datos sobre la } \\
\text { segregación escolar? }\end{array}$ & $\begin{array}{l}\text { ¿Disponéis de información sobre la } \\
\text { segregación escolar?. ¿Qué tipo de } \\
\text { datos? }\end{array}$ \\
\hline $\mathrm{C} 1$ & - No. & - No. No disponemos de ningún dato. \\
\hline $\mathrm{C} 2$ & $\begin{array}{l}\text { - No. No se recogen datos de } \\
\text { manera explícita gobre la } \\
\text { segregación escolar. }\end{array}$ & $\begin{array}{l}\text { - Se disponen de datos anuales sobre indica- } \\
\text { dores que pueden influir en la segregación } \\
\text { (porcentaje de matrícula de inmigrantes, ab- } \\
\text { sentismo escolar, solicitud de subvenciones...). }\end{array}$ \\
\hline C3 & $\begin{array}{l}\text { - Sí, a través del Consorcio de } \\
\text { Educación }\end{array}$ & $\begin{array}{l}\text { - información sobre concentración de alum- } \\
\text { nado inmigrante no comunitario, ayudas } \\
\text { sociales, flujos de movilidad, desigualdad } \\
\text { territorial, costes de escolarización. }\end{array}$ \\
\hline $\mathrm{C} 4$ & $\begin{array}{l}\text { - No hay recogida de datos } \\
\text { específica sobre la segre- } \\
\text { gación escolar. Se realizan } \\
\text { estimaciones intuitivas. }\end{array}$ & $\begin{array}{l}\text { - Los datos que disponemos sobre se- } \\
\text { gregación escolar son muy genéricos y } \\
\text { asociados al estudio diagnóstico de los } \\
\text { barrios. Se intuye una incidencia de tipo } \\
\text { urbanístico, de concentración de población } \\
\text { con limitada formación y bajas expectati- } \\
\text { vas educativas. También seposeen datos } \\
\text { de la comisión local de absentismo escolar. }\end{array}$ \\
\hline C5 & $\begin{array}{l}\text { - No. Se recogen datos rela- } \\
\text { cionados con la segregación } \\
\text { escolar, pero muy simples. }\end{array}$ & $\begin{array}{l}\text { - Tenemos datos sobre distribución del } \\
\text { alumnado del municipio (solicitudes por } \\
\text { redes, vacantes, por etapas...). }\end{array}$ \\
\hline C7 & $\begin{array}{l}\text { - No. En el municipio re- } \\
\text { cogemos algunos datos } \\
\text { relacionados. }\end{array}$ & $\begin{array}{l}\text { - En el municipio se trabaja m red. Se reúne la } \\
\text { Comisión de Escolarización y la Inspección } \\
\text { facilita algunos datos sobre alumnado con } \\
\text { necesidades educativas especiales (NEE). } \\
\text { También colaboran los Servicios Sociales. }\end{array}$ \\
\hline C8 & $\begin{array}{l}\text { - No se recogen datos sobre } \\
\text { segregación escolar. }\end{array}$ & $\begin{array}{l}\text { - La Comisión de Escolarización tiene datos } \\
\text { sobre escolarización, nacionalidades e } \\
\text { inmigración. }\end{array}$ \\
\hline C10 & $\begin{array}{l}\text { - No sobre segregación escolar. } \\
\text { El ayuntamiento posee un } \\
\text { Servicio de Estudios y Análisis } \\
\text { de la Información que nos } \\
\text { proporciona datos socioeconó- } \\
\text { micos de los barrios, pero no } \\
\text { de los centros escolares. No } \\
\text { podemos decir que sea fiable. }\end{array}$ & $\begin{array}{l}\text { - Se elaboran datos sobre niveles socio- } \\
\text { económicos de las escuelas, a partir de las } \\
\text { becas de comedor y del número de matri- } \\
\text { culaciones. También se tienen en cuenta } \\
\text { los datos de la Generalitat sobre el alum- } \\
\text { nado connecesidades de apoyo educativo. }\end{array}$ \\
\hline
\end{tabular}

(continúa) 


\begin{tabular}{|c|c|c|}
\hline Ciudad & $\begin{array}{l}\text { En tu municipio. ¿se } \\
\text { recogen datos sobre la } \\
\text { segregación escolar? }\end{array}$ & $\begin{array}{l}\text { ¿Disponéis de información sobre la } \\
\text { segregación escolar? ¿Qué tipo de } \\
\text { datos? }\end{array}$ \\
\hline C12 & $\begin{array}{l}\text { - No. Solo tenemos datos } \\
\text { sobre la concentración de } \\
\text { alumnado con necesidades } \\
\text { específicas de apoyo (NEA) } \\
\text { y recién llegados. }\end{array}$ & $\begin{array}{l}\text { - Tenemos datos por centros sobre los in- } \\
\text { dicadores mencionados y estimamos las } \\
\text { diferencias entre centros. }\end{array}$ \\
\hline C13 & $\begin{array}{l}\text { - No de manera concreta. Se } \\
\text { recogen datos sobre esco- } \\
\text { larización. desagregando } \\
\text { alumnado con NEA. Hacemos } \\
\text { estimaciones con estos datos. }\end{array}$ & $\begin{array}{l}\text { - Se tienen datos sobre asistencia de alumnado } \\
\text { a clase, grado de integración, comportamien- } \\
\text { to y normas de convivencia, competencias } \\
\text { instrumentales, promoción de curso, repeti- } \\
\text { ción, NEEy expulsiones del centro. }\end{array}$ \\
\hline C15 & $\begin{array}{l}\text { - Sí disponemos de datos. } \\
\text { Tenemos un convenio con la } \\
\text { Universidad X sobreel estado } \\
\text { de este tema. }\end{array}$ & $\begin{array}{l}\text { - Tenemos datos sobre escolarización para } \\
\text { revisar las zonas escolares y disminuir la se- } \\
\text { gregación. Se han adoptado medidas sobre } \\
\text { el alumnado con NEE y NEA, ratios para la } \\
\text { matrícula vivay así evitar la acumulación. }\end{array}$ \\
\hline C21 & $\begin{array}{l}\text { - Sí tenemos datos. Se han } \\
\text { obtenido mediante un con- } \\
\text { venio entre el municipio y el } \\
\text { Departamento de Educación } \\
\text { del Gobierno X. }\end{array}$ & $\begin{array}{l}\text { - Sí. Disponemos de un flujo de información } \\
\text { continuo desde el Departamento de Edu- } \\
\text { cación del gobierno autonómico (Sección } \\
\text { de Estadística). }\end{array}$ \\
\hline
\end{tabular}

Fuente: Elaboración propia

las Comunidades Autónomas tienen información sobre este tema, pero no parecen estar dispuestos a compartirla con todos los municipios (C6). En el caso de la ciudad C21 (capital de una Comunidad Autónoma), la Administración le ofrece datos de los resultados de las pruebas de diagnóstico de las asignaturas instrumentales desglosados por centro educativo, índices socioeconómicos de barrios y zonas, etc. Parece pues existir una diferencia de trato en función del tamaño de las ciudades. Las grandes ciudades y las medianas de la muestra obtienen datos objetivos y fiables de la Administración Autonómica sobre el fenómeno de la segregación escolar (vía convenio), mientras que las ciudades medianas integradas en áreas metropolitanas y las pequeñas carecen de la información necesaria (se basan en estimaciones) para diagnosticar la magnitud del problema y diseñar actuaciones de intervención.

En muy pocas corporaciones locales se trabaja de manera transversal (entre Administraciones, Universidades, Consorcios...), y en la misma corporación no todas las concejalías están sensibilizadas de la misma manera con este problema. En general, las que más se implican son las concejalías de 

CAMINANDO HACIA EL DESARROLLO SOSTENIBLE

Educación, Servicios Sociales y Cultura. En la ciudad C21 también se subraya la importancia de activar los Consejos Escolares de cada centro y municipio para compartir información y planificar intervenciones coordinadas entre las diversas instituciones comunitarias.

\subsection{Las intervenciones de las ciudades educadoras ante la segregación escolar}

Como resultados se exponen en la Tabla 4 los datos aportados por los técnicos y las técnicas sobre las medidas adoptadas por aquellos municipios que tienen planes específicos para abordar el problema de la segregación escolar.

Dada la complejidad del problema, parece obvio que las intervenciones para paliar la segregación escolar deben ser diversas e interdisciplinares. Las propuestas de las ciudades participantes recogidas en la Tabla 4 se fundamentan en un plan integral contra la segregación escolar. Este plan desarrolla programas y proyectos diferentes en función de la actuación de las Administraciones y concejalías responsables. Sin embargo, no todos los planes contra la segregación escolar están apoyados por el gobierno autonómico-regional. La mayoría son creados de forma independiente por municipios sensibilizados y comprometidos con el bienestar de la ciudadanía.

Respecto a la intervención en el ámbito educativo, los representantes de las ciudades participantes en el estudio exponen actuaciones relacionadas con la orientación de las familias en los procesos de selección de centro mediante la creación de Oficinas Municipales de Escolarización (OME), la detección precoz de alumnado con necesidades educativas de apoyo, el análisis del mapa escolar y la orientación, y la ayuda a familias y estudiantes en la transición de los centros de primaria a los institutos de secundaria (C6). Respecto a la previsión de puestos escolares, se analiza la reserva de plazas para el alumnado de incorporación tardía, el cierre de escuelas en crisis y la creación de nuevos centros con proyectos educativos innovadores (Magnet, Escola Nova, Tandem...). También se refuerza la oferta de actividades extraescolares y se controlan las posibles prácticas discriminatorias de los centros educativos (C14, C15 y C21). Lamentablemente, solamente 3 de las 21 ciudades participan en reuniones de coordinación con la Administración Autonómica para abordar este problema (C3, C15 y C21).

En el ámbito familiar, se desarrollan políticas activas de inclusión en los diferentes barrios y zonas de la ciudad (Proyecto Mincome) (C3). También se impulsan medidas relacionadas con la orientación y el acompañamiento de las familias en el proceso de escolarización de sus hijos e hijas (C6 y C14), políticas relacionadas con el acercamiento de recursos a las familias más necesitadas (becas, ayudas, material didáctico, promover la socialización de los recursos, oferta de actividades extraescolares...) e impulso de la Educación Infantil de primer ciclo (0-3 años). 
226 PEDRO MOISÉS ARAMENDI JÁUREGUI, ITZIAR REKALDE-RODRÍGUEZ, Y ESTHER CRUZ IGLESIAS LAS CIUDADES EDUCADORAS ANTE LA SEGREGACIÓN ESCOLAR: CAMINANDO HACIA EL DESARROLLO SOSTENIBLE

TABLA 4

INTERVENCIÓN DE LAS CIUDADES EDUCADORAS

ANTE LA SEgREGACIÓN ESCOLAR (RESUMEN)

\begin{tabular}{|c|c|c|}
\hline Ciudad & $\begin{array}{l}\text { ¿Qué medidas específicas desarrollan los } \\
\text { ayuntamientos para paliar los efectos } \\
\text { negativos de la Segregación Escolar? }\end{array}$ & $\begin{array}{l}\text { Identifica experien- } \\
\text { cias de intervención } \\
\text { municipal ante la } \\
\text { Segregación Escolar } \\
\text { que se realizan en } \\
\text { vuestra ciudad }\end{array}$ \\
\hline C3 & $\begin{array}{l}\text { - Plan contra la segregación escolar 2019-20. El } \\
\text { plan de choque incluye el trabajo integral con el } \\
\text { alumnado. Las orientaciones tienen como marco } \\
\text { de referencia el Pacto contra la Segregación Esco- } \\
\text { lar del Síndic de Greuges (Defensor del Pueblo), } \\
\text { tanto en la escuela pública como en la concertada. } \\
\text { - Políticas culturales: Alianza Cultura y Educación. } \\
\text { - Política familiar: Proyecto B. Mineome que desa- } \\
\text { rrolla políticas activas de inclusión en los barrios } \\
\text { del eje X. } \\
\text { - Política de economía y empleo, política de vivienda } \\
\text { y urbanismo, política de movilidad, accesibilidad y } \\
\text { transporte, política de comunidad y de integración, } \\
\text { plan de barrios (el objetivo principal es revertir } \\
\text { las desigualdades sociales entre los barrios de la } \\
\text { ciudad), políticas de igualdad de oportunidades, } \\
\text { género, feminismo. Impregnar todas las políticas } \\
\text { municipales con un enfoque de género. }\end{array}$ & $\begin{array}{l}\text { - La Estrategia Local con } \\
\text { el Pueblo Gitano es un } \\
\text { plan de actuación para } \\
\text { luchar contra las des- } \\
\text { igualdades con las que } \\
\text { se pueden encontrar } \\
\text { estas personas, incidien- } \\
\text { do especialmente en } \\
\text { los ámbitos de la edu- } \\
\text { cación, salud, trabajo y } \\
\text { vivienda. }\end{array}$ \\
\hline C6 & $\begin{array}{l}\text { - Ajustar la oferta de plazas escolares: detección } \\
\text { precoz del alumnado con necesidades edu- } \\
\text { cativas especiales (NEE) y reserva de plazas, } \\
\text { adscripciones de centros de primaria a los de } \\
\text { secundaria, análisis de zonas escolares (áreas de } \\
\text { influencia para aplicar el criterio de proximidad). } \\
\text { - Medidas de acompañamiento y orientación para } \\
\text { las familias: Oficinas Municipales de Escolariza- } \\
\text { ción (OME). } \\
\text { - Medidas para mejorar la oferta educativa: pro- } \\
\text { yectos de innovación singulares en cada centro, } \\
\text { Proyecto Magnet, Escola Nova } 21 \text {, Tandem. Ac- } \\
\text { tividades extraescolares, acciones de mejora y } \\
\text { mantenimiento de los edificios escolares (cuidar } \\
\text { la imagen). } \\
\text { - Igualdad de oportunidades: acceso a servicios de } \\
\text { comedor, transporte y actividades extraescolares. }\end{array}$ & $\begin{array}{l}\text { - La ciudad ha iniciado un } \\
\text { plan a medio plazo para } \\
\text { la mejora de la escolari- } \\
\text { zación con una voluntad } \\
\text { clara de erradicar la } \\
\text { segregación escolar. }\end{array}$ \\
\hline
\end{tabular}

(continúa) 
CAMINANDO HACIA EL DESARROLLO SOSTENIBLE

\begin{tabular}{|c|c|c|}
\hline Ciudad & $\begin{array}{l}\text { ¿Qué medidas específicas desarrollan los } \\
\text { ayuntamientos para paliar los efectos } \\
\text { negativos de la Segregación Escolar? }\end{array}$ & $\begin{array}{l}\text { Identifica experien- } \\
\text { cias de intervención } \\
\text { municipal ante la } \\
\text { Segregación Escolar } \\
\text { que se realizan en } \\
\text { vuestra ciudad }\end{array}$ \\
\hline C14 & $\begin{array}{l}\text { - Políticas focalizadas en la oferta: ajuste en la } \\
\text { oferta de plazas, apertura o cierre de líneas, } \\
\text { mejoras en la detección de las NEE, reserva de } \\
\text { plazas, adscripciones entre centros de primaria y } \\
\text { de secundaria, zonificación escolar. } \\
\text { - Políticas de gestión de la escolarización: gestión } \\
\text { de la matrícula viva, reducción o aumento de ra- } \\
\text { tios, control de fraude en los empadronamientos } \\
\text { y en la certificación de enfermedades digestivas. } \\
\text { - Políticas dirigidas a las familias: políticas de } \\
\text { información, medidas de acompañamiento en el } \\
\text { proceso de escolarización y refuerzo de las Ofi- } \\
\text { cinas Municipales de Escolarización. } \\
\text { - Políticas para mejorar la calidad y el atractivo de } \\
\text { los centros. } \\
\text { - Políticas para garantizar la accesibilidad a los re- } \\
\text { cursos: becas y ayudas para comedores escolares, } \\
\text { libros y material escolar, promover la socialización } \\
\text { de recursos, tarifación social versus tarifa única. } \\
\text { - Políticas que contemplen aspectos más allá de } \\
\text { la formación obligatoria y reglada: oferta de } \\
\text { Escuelas Bressol (escuelas 0-3 años) y servicios } \\
\text { complementarios para esa edad, el acceso a las } \\
\text { ofertas educativas no regladas y complementarias } \\
\text { (música, arte, deporte, educación y tiempo libre). } \\
\text { - Políticas culturales: ofertas culturales para todos } \\
\text { los públicos, que lleguen a todos los barrios de } \\
\text { la ciudad, que faciliten la accesibilidad a las dis- } \\
\text { tintas economías, que promuevan la interacción } \\
\text { entre públicos, intereses, generaciones y culturas. } \\
\text { - Política familiar: Programas de soporte a la fa- } \\
\text { milia desde la óptica de la formación, recursos y } \\
\text { servicios para su completo desarrollo. Políticas } \\
\text { de empoderamiento. } \\
\text { - Política de economía y empleo: generar ser- } \\
\text { vicios de soporte a la creación de empleo y } \\
\text { formación profesional. }\end{array}$ & $\begin{array}{l}\text { - Apoyo al colectivo gita- } \\
\text { no de la zona norte de } \\
\text { la ciudad. } \\
\text { - Gestión unificada de } \\
\text { comedores escolares } \\
\text { desde el ayuntamiento. } \\
\text { - Oferta de actividades } \\
\text { extraescolares coordinada } \\
\text { con los centros escolares. } \\
\text { Programa piloto. } \\
\text { - Figura de coordinador/a } \\
\text { de actividades } \\
\text { extraescolares del ayun- } \\
\text { tamiento. } \\
\text { - Plan municipal de apo- } \\
\text { yo a los institutos. } \\
\text { - Oficina municipal de } \\
\text { acompañamiento a las } \\
\text { familias. } \\
\text { - Guía de recursos edu- } \\
\text { cativos. }\end{array}$ \\
\hline
\end{tabular}




\begin{tabular}{|c|c|c|}
\hline Ciudad & $\begin{array}{l}\text { ¿Qué medidas específicas desarrollan los } \\
\text { ayuntamientos para paliar los efectos } \\
\text { negativos de la Segregación Escolar? }\end{array}$ & $\begin{array}{l}\text { Identifica experien- } \\
\text { cias de intervención } \\
\text { municipal ante la } \\
\text { Segregación Escolar } \\
\text { que se realizan en } \\
\text { vuestra ciudad }\end{array}$ \\
\hline & $\begin{array}{l}\text { - Política de vivienda y urbanismo: planificación } \\
\text { de barrios y ciudades desde una perspec- } \\
\text { tiva de la inclusión de los distintos niveles } \\
\text { económicos y culturales y que transforman } \\
\text { paulatinamente los déficits de los que ya están } \\
\text { construidos, planes ambiciosos de regenera- } \\
\text { ción de barrios. } \\
\text { - Política de movilidad, accesibilidad y trans- } \\
\text { porte: garantizar la facilidad del transporte, } \\
\text { especialmente de las zonas con más dificultades } \\
\text { (analizar líneas y frecuencias superando los } \\
\text { aspectos de rentabilidad económica), políticas } \\
\text { de bonificación o de acceso libre. } \\
\text { - Políticas de igualdad de oportunidades, género, } \\
\text { feminismo: detección de los elementos cons- } \\
\text { titutivos de las desigualdades, campañas de } \\
\text { concienciación, de reivindicación y proyectos } \\
\text { educativos, no únicamente escolares, que par- } \\
\text { ticipen de esta visión e impulsen el cambio de } \\
\text { acciones. Es decir, que superen la fase ideológi- } \\
\text { ca o discursiva y lleguen al cambio mediante la } \\
\text { acción (medidas concretas). }\end{array}$ & \\
\hline C15 & $\begin{array}{l}\text { - La Consejería de Educación de X tiene como } \\
\text { uno de sus objetivos prioritarios políticos } \\
\text { 2015-2019 reducir la segregación escolar en el } \\
\text { municipio (la capital) alineada con los Objetivos } \\
\text { de Desarrollo Sostenible de la agenda } 2030 \text { en } \\
\text { su punto } 4 \text { (Educación). } \\
\text { - Políticas focalizadas en la oferta: análisis de las } \\
\text { zonificacion escolares, adscripciones entre los } \\
\text { centros de primaria y secundaria, reserva de pla- } \\
\text { zas y detección de alumnado con NEE, cierre de } \\
\text { líneas de grupos, ajuste de la oferta a las plazas. } \\
\text { - Políticas para la mejora de los recursos: fomento } \\
\text { de la innovación educativa (Proyectos Magnet), } \\
\text { reforzar la calidad educativa de los centros, fa- } \\
\text { vorecer la oferta de actividades extraescolares. }\end{array}$ & $\begin{array}{l}\text { - Estudio sobre la segre- } \\
\text { gación escolar en el } \\
\text { municipio (Consejería } \\
\text { de Educación). } \\
\text { - Proyección demográfica } \\
\text { 2018-2022 para la plani- } \\
\text { ficación educativa. }\end{array}$ \\
\hline
\end{tabular}


PEDRO MOISÉS ARAMENDI JÁUREGUI, ITZIAR REKALDE-RODRÍGUEZ, Y ESTHER CRUZ IGLESIAS

LAS CIUDADES EDUCADORAS ANTE LA SEGREGACIÓN ESCOLAR:

CAMINANDO HACIA EL DESARROLLO SOSTENIBLE

\begin{tabular}{|c|c|c|}
\hline Ciudad & $\begin{array}{l}\text { ¿Qué medidas específicas desarrollan los } \\
\text { ayuntamientos para paliar los efectos } \\
\text { negativos de la Segregación Escolar? }\end{array}$ & $\begin{array}{l}\text { Identifica experien- } \\
\text { cias de intervención } \\
\text { municipal ante la } \\
\text { Segregación Escolar } \\
\text { que se realizan en } \\
\text { vuestra ciudad }\end{array}$ \\
\hline C21 & $\begin{array}{l}\text { - Acordar con la Administración Educativa compe- } \\
\text { tente el modelo de intervención a desarrollar. } \\
\text { - Planes de Ordenación Urbana: medidas que } \\
\text { limiten la segregación urbanística (no concen- } \\
\text { trar viviendas de protección oficial, espacios de } \\
\text { encuentro en barrios, facilitar la comunicación } \\
\text { entre las distintas zonas de la ciudad...). } \\
\text { - Desarrollar diagnósticos individualizados en los } \\
\text { centros escolares más vulnerables que permitan } \\
\text { conocer sus necesidades y desarrollar planes de } \\
\text { intervención específicos. } \\
\text { - Controlar las cuotas para el desarrollo de ac- } \\
\text { tividades complementarias y extraescolares } \\
\text { (estableciendo importes para las familias con } \\
\text { rentas bajas). } \\
\text { - Participar en las Comisiones de garantías del } \\
\text { Gobierno Autonómico (en las mismas se debate } \\
\text { sobre el proceso de matriculación del alumnado } \\
\text { recién llegado). } \\
\text { - Estudiar el impacto de la diversidad religiosa y } \\
\text { el laicismo en el acceso a los centros educativos. } \\
\text { - Fomentar el encuentro y la cooperación entre } \\
\text { Asociaciones de Madres y Padres (AMPA) de } \\
\text { escuelas diferentes. Ofertar actividades extraes- } \\
\text { colares zonales sin afectar a las actividades que } \\
\text { organizan las AMPAs de los centros. } \\
\text { - Posibilitar el acceso gratuito de menores de } \\
\text { familias en situación de vulnerabilidad socioeco- } \\
\text { nómica en el primer ciclo de Educación Infantil } \\
\text { (Escuelas Infantiles Municipales). }\end{array}$ & $\begin{array}{l}\text { - Proyecto con AMPAs y } \\
\text { coordinado con el pro- } \\
\text { grama Hamaika Esku. } \\
\text { - Pruebas diagnósticas } \\
\text { para prevenir el fracaso } \\
\text { escolar. }\end{array}$ \\
\hline
\end{tabular}

Fuente: Elaboración propia

En la politica de servicios sociales y vivienda, se identifican iniciativas relacionadas con la igualdad de oportunidades, empoderamiento de familias, políticas de igualdad de género y acceso a transporte y comedor escolar (C3 y C14). En el ámbito de la economía, se promueve la creación de empleo y el fomento de la formación profesional. La política urbanística también es un aspecto fundamental para el impulso de la cohesión social. Se desarrollan planes de regeneración de 
barrios para corregir desigualdades (Plan de Ordenación Urbana, C21), se facilita el acceso a la vivienda, las actuaciones en el ámbito de la movilidad, accesibilidad y transporte desde la perspectiva inclusiva (C14).

Finalmente, en el ámbito cultural, la actuación de las ciudades se basa en el principio de inclusión e igualdad de oportunidades, fomentando la atención a la diversidad y el impulso de las interacciones entre la ciudadanía. Para lograrlo, se procura garantizar que la oferta cultural sea asequible, de forma que cualquier ciudadano o ciudadana pueda acceder a ella (C21).

Así mismo, los y las representantes de las ciudades educadoras presentan experiencias de intervención municipal realizadas con diferentes sectores sociales (colectivo gitano, marroquí, familias inmigrantes y de nivel socioeconómico bajo) y con servicios profesionales especializados.

\section{DiscuSión Y CONCLUSIONES}

Teniendo en cuenta los resultados obtenidos en el estudio realizado con las 21 ciudades educadoras participantes, podemos extraer las siguientes conclusiones discutidas:

Se percibe que la mayoría de las ciudades no poseen datos específicos sobre el problema de la segregación escolar y que la Administración Autonómica, según sus técnicos y técnicas, tampoco parece estar demasiado predispuesta a compartirlos. La escasez de información dificulta el conocimiento exhaustivo del problema y la selección de alternativas adecuadas a cada situación (Lubián, 2016). No obstante, a diferencia de los pequeños municipios, se constata que algunas capitales de provincia logran información y ayuda de la Administración Autonómica, mediante la ejecución de convenios, creando un agravio comparativo respecto a las ciudades con menos población. Además, algunas capitales autonómicas han creado instituciones que gestionan la formación de los docentes e, incluso, la innovación de los centros educativos de la ciudad (Vila, 2018).

Las personas participantes en el estudio afirman que hay gran diversidad de causas que originan la segregación escolar y, por tanto, nos lleva a concluir que las alternativas de solución también son múltiples y dependientes de las variables contextuales, económicas, sociales y culturales de la ciudad educadora. Como señalan Ortiz (2014) y Finnvold, (2018), las causas que explican la segregación escolar están estrechamente relacionadas con factores socioeconómicos, socioculturales y urbanísticos. Algunos de estos factores se retroalimentan entre sí, complicando aún más el problema (Erickson y Highsmith, 2018). Se trata de complejos procesos de construcción de la diferencia que generan desequilibrios y, en consecuencia, ciudades más fragmentadas (Pallarés et al., 2017).

Los y las representantes de las ciudades educadoras afirman que la segregación escolar afecta de forma sensible a aspectos educativos y familiares y, fundamentalmente, al ámbito social. A nivel educativo, se constata la existencia de segregación 
escolar intra y entre redes de enseñanza (Owens, 2018). La opinión generalizada de los representantes de las ciudades es que la misma política de la Administración Educativa provoca situaciones de segregación interna e inter-escolar (Pàmies, 2013), de guetización (Martínez y Ferrer, 2018) y efectos sistémicos complejos (Cote, 2018). Una consecuencia de esta situación es el efecto buido de las familias que no desean que sus hijos e hijas compartan estudios con estudiantes de otras clases y colectivos sociales (Liebowitz, 2018). Lamentablemente, existe un proceso de aculturación de colectivos de origen inmigrante, sin que se produzca su inclusión plena en la sociedad, y como sabemos, las ciudades educadoras deben apostar por el fomento de la igualdad de oportunidades y la creación de espacios sociales integradores (Murillo y Martínez-Garrido, 2019) que eliminen las barreras a la participación de todas las personas que habitan en ellas. Pero, como ya nos advertía Valiente (2008), el éxito de estas políticas no va a depender únicamente de su diseño, sino de la capacidad de cada contexto, para modular la influencia de los factores de segregación escolar.

Se concluye que el fenómeno analizado es de gran magnitud y, por tanto, las medidas deben ser adecuadas a su complejidad. El liderazgo de las corporaciones locales y, el diálogo y el entendimiento entre las diversas Administraciones son piezas esenciales para generar estrategias articuladas de intervención (Guillén y Hernández, 2018). Sin embargo, la actuación de los municipios queda sensiblemente mermada por la falta de competencias educativas y de bienestar social (Moreno, 2012). En este sentido, en el Estado español existe una fuerte tendencia centralizadora (las decisiones educativas más importantes están en manos del Estado y las Comunidades Autónomas), sin que la descentralización haya llegado a las corporaciones locales (Frías, 2007). Esta circunstancia limita sensiblemente la actuación de los municipios en el ámbito educativo y, concretamente, en el abordaje de la segregación escolar. Aunque la descentralización de competencias hacia las corporaciones locales parece difícil en el Estado español, sí podría ser factible la desconcentración de estas. Es decir, ceder la competencia al municipio durante un tiempo determinado mediante la creación de convenios específicos, fomentando estructuras interinstitucionales que permitan hacer realidad el derecho a la educación de toda la ciudadanía, especialmente de los más vulnerables (Amaro y Navarro, 2013).

El abordaje eficaz y sostenible de este problema, partiendo del marco de los ODS adoptado por la AICE, exige desarrollar políticas y actuaciones transversales; lograr un alto nivel de coordinación entre las diversas Administraciones (estatal, autonómica, y local) y apelar a la responsabilidad e implicación de la clase política. Para caminar hacia ello, las propuestas que se derivan de este estudio subrayan las implicaciones de las políticas locales de las ciudades educadoras en términos de desarrollo sostenible:

- Establecer mecanismos de trasvase de información respecto a la segregación escolar desde las administraciones estatal y autonómica a las ciudades educadoras. 
Todas las localidades, con independencia de su tamaño, deben de tener derecho a acceder, generar y compartir información que les facilite la comprensión del fenómeno de la segregación escolar de su ciudad y su posterior intervención.

- Realizar un diagnóstico exhaustivo de los efectos económicos, culturales, sociales y de sostenibilidad que genera la segregación escolar en las ciudades educadoras.

- Diseñar proyectos estratégicos que compensen de manera equitativa la influencia de los factores que inciden en la segregación escolar para minimizar sus efectos.

- Desconcentrar las competencias en materia de inclusión social en las corporaciones locales, de tal manera que se establezcan convenios específicos que fomenten estructuras interinstitucionales.

- Respaldar políticas educativas que fomenten un planteamiento ecológico, desde una visión global y abierta teniendo en cuenta la naturaleza acogedora de las ciudades educadoras. De tal manera que se traspase el contexto de la educación formal intramuros y se llegue a espacios naturales y abiertos de aprendizaje, donde las ciudades educadoras tienen un largo y prometedor camino por recorrer.

\section{REFERENCIAS BIBLIOGRÁFICAS}

Ainscow, M. (2004). Desarrollo de escuelas inclusivas. Narcea.

Aldana, Y., y Rodríguez, L. C. (2018). Las ondas ciudadanas en la escuela. Comunicación, 38, 11-28. http://doi.org/10.18566/comunica.n38.a02

Alegre, M. A. (2008). Educación e inmigración. ¿Un binomio problemático? Revista de Educación, 345, 61-82.

Amaro, A., y Navarro, D. (2013). Agentes externos, Ciudades Educadoras e Inclusión. Ejes del cambio en las aulas. Historia y comunicación social, 18 (3), 449-460. http://doi. org/10.5209/rev_HICS.2013.v18.44341

Apple, M. W. (2015). Reflections on the Educational Crisis and Tasks of the Critical Scholars/ Activist. Nordic Journal of Pedagogy and Critique, 1, 1-17. http://doi.org/10.17585/ ntpk.v1.90

Asociación Internacional de Ciudades Educadoras [AICE]. (2004). Carta de Ciudades Educadoras. https://www.edcities.org/carta-de-ciudades-educadoras/

Benito, R., y González, I. (2013). ¿Puede el efecto composición reducir las desigualdades educativas? Una mirada sobre los efectos de la segregación escolar en España y los países del modelo de integración uniforme. RASE, 6(1), 49-71. https://ojs.uv.es/index. $\mathrm{php/RASE} / \mathrm{article} / \mathrm{view} / 8597$

Bellei, C. C. (2013). El estudio de la segregación socioeconómica y académica de la educación chilena. Estudios Pedagógicos 39(1), 325-345. https://doi.org/10.4067/S071807052013000100019 
PEDRO MOISÉS ARAMENDI JÁUREGUI, ITZIAR REKALDE-RODRÍGUEZ, Y ESTHER CRUZ IGLESIAS LAS CIUDADES EDUCADORAS ANTE LA SEGREGACIÓN ESCOLAR:

CAMINANDO HACIA EL DESARROLLO SOSTENIBLE

Billingham, C. M. (2019). Within-District Racial Segregation and the Elusiveness of White Student Return to Urban Public Schools. Urban Education, 54(2), 151-181. https://doi. org/10.1177/0042085915618713

Bisquerra, R. (Coord.) (2012). Metodología de la investigación educativa. La Muralla.

Bonal, X. (2018). La política educativa ante el reto de la segregación escolar en Cataluña. UNESCO.

Bonal, X., y Verger, A. (2016). Privatización educativa y globalización: una realidad poliédrica. RASE, 9(2), 175-180. https://ojs.uv.es/index.php/RASE/article/view/8413

Brown, J., e Isaacs, D. (2006). World Café. El nuevo paradigma de comunicación organizacional y social. CECSA.

Casas, J, Repullo, J. R., y Donado, J. (2003). La encuesta como técnica de investigación. Elaboración de cuestionarios y tratamiento estadístico de los datos. Atención primaria, 31(8), 527-538. https://doi.org/10.1016/S0212-6567(03)70728-8

Carbonell, J. (2016). Ciudad Educadora. Pedagogías del siglo XXI. Octaedro.

Coffey, A., y Atkinson, P. (2003). Encontrar sentido a los datos cualitativos. Contus.

Comité de Ética para las Investigaciones relacionadas con los Seres Humanos de la UPV/ EHU -CEISH- (2020). https://www.ehu.eus/eu/web/ceid/ceish/comite

Cote, D. A. (2018). Ciudad y Educación: Persistencias, transformaciones y correspondencias de un vínculo inmanente. Praxis \& Saber, 9, 119-141. https://doi.org/10.19053/22160159. v9.n19.2018.8299

Donato, R., \& Hanson, J. (2019). Mexican-American resistance to school segregation. Phi Delta Kappan, 100 (5), 39-42. https://doi.org/10.1177/0031721719827545

Dos Santos Figueiredo, Y. D., Prim, M. A., \& Dandolini, G.A. (2021). Educating city: A media for social innovation. Smart Innovation, Systems and Technologies, 198, 251-260. https:// doi.org/10.1007/978-3-030-55374-6_25

Erickson, A. T., \& Highsmith, A. R. (2018). The Neighborhood Unit: Schools, Segregation, and the Shaping of the Modern Metropolitan Landscape. Teachers College Record, 120(3), 1-36. https://doi.org/10.1177/016146811812000308

Finnvold, J. E. (2018). School segregation and social participation: the case of Norwegian children with physical disabilities. European Journal of Special Needs Education, 33(2), 187-204. https://doi.org/10.1080/08856257.2018.1424781

Flick, U. (2011). Introducing research methodology. A beginner's guide to doing a research project. Sage.

Frías, A. S. (2007). La educación y la Administración local. Participación Educativa, 6, 5-21.

Goetz, J. P., y Lecompte, M. D. (1988). Etnografía y diseño cualitativo en investigación educativa. Morata.

Grundy, S. (1991). Producto y praxis del currículum. Morata.

Guillén, R., y Hernández, A. M. (2018). La colaboración de la escuela y las instituciones culturales para la Educación Patrimonial: estudio de caso. Clio, History and History Teaching, 44, 146-169.

Hernández, M., y Raczynski, D. (2015). Elección de escuela en Chile: De las dinámicas de distinción y exclusión a la segregación socioeconómica del sistema escolar. Estudios Pedagógicos 41(2), 127-141. https://doi.org/10.4067/S0718-07052015000200008 
PEDRO MOISÉS ARAMENDI JÁUREGUI, ITZIAR REKALDE-RODRÍGUEZ, Y ESTHER CRUZ IGLESIAS LAS CIUDADES EDUCADORAS ANTE LA SEGREGACIÓN ESCOLAR: CAMINANDO HACIA EL DESARROLLO SOSTENIBLE

Janesick, V. (2000). The Choreography of Qualitative Research Design: Minuets, Improvisations, and Crystallization. En N. K. Denzin \& Y. S. Lincoln (Eds.). The Handbook of Qualitative Research (pp. 379-400). Sage Pub.

Jimenez, O. (2017). Euskal Herriko herri eta hiri hezitzaileen errealitatearen analisia erakunde eta komunitate ikuspegitik. Praktika onen ekarpena gizarte berrikuntzari. Tesis doctoral inédita. Universidad del País Vasco/Euskal Herriko Unibertsitatea.

Jordá, A. (2020). La gran diferencia entre las grandes ciudades y el resto de los territorios. Blog Política Comunicada. https://ciudadinnova.blogspot.com/2020/11/

Kearns, P. (2015). Learning cities on the move. Australian Journal of Adult Learning, 55(1), 153-168.

Liebowitz, D. D. (2018). Ending to What End? The Impact of the Termination of Court-Desegregation Orders on Residential Segregation and School Dropout Rates. Educational Evaluation and Policy Analysis, 40(1), 103-128. https://doi. org/10.3102/0162373717725804

Lubián, C. (2016). La escolarización del alumnado de nacionalidad extranjera en la ciudad de Granada. Diferencias por nacionalidad y el papel de la red privada-concertada. RASE, 9(2), 212-231.

Lukas, J. F., y Santiago, K. (2016). Hezkuntza Ebaluazioa. Universidad del País Vasco/Euskal Herriko Unibertsitatea.

Macartney, H., \& Singleton, J. D. (2017). School boards and student segregation. Journal of Public Economics, 164, 165-182. https://doi.org/10.1016/j.jpubeco.2018.05.011

Martínez, L., y Ferrer, A. (2018). Mézclate conmigo. De la segregación económica a la inclusión educativa. Save The Children-España.

Moreno, J. L. (2012). Ayuntamientos y desarrollo educativo. Popular.

Murillo, F. J. (2016). Midiendo la segregación escolar en América Latina. Un análisis metodológico utilizando el TERCE. REICE. Revista Iberoamericana sobre Calidad, Eficacia y Cambio en Educación, 14(4), 33-60. https://doi.org/10.15366/reice2016.14.4.002

Murillo, F. J., y Martínez-Garrido, C. (2019). Perfiles de segregación escolar por nivel socioeconómico en España y sus Comunidades Autónomas. RELIEVE, 25(1), 1-20. http://doi. org/10.7203/relieve.25.1.12917

Murillo, F. J., Martínez-Garrido, C., y Belavi, G. (2017). Segregación escolar por origen nacional en España. Obets, 12(2), 395-423. https://doi.org/10.14198/OBETS2017.12.2.04

Organización de Naciones Unidas -ONU- (2015). Transversalización de la Agenda 2030 para el Desarrollo Sostenible. https://unsdg.un.org/sites/default/files/UNDG-Mainstreamingthe-2030-Agenda-Reference-Guide_Spanish-clean.pdf

Ortiz, M. (2014). Inmigración, Escuela y Exclusión. Empiria. Revista de Metodología de Ciencias Sociales, 28, 59-78. https://doi.org/10.5944/empiria.28.2014.12121

Owens, A. (2018). Income Segregation between School Districts and Inequality in Students Acievement. Sociology of Educaction, 91(1), 1-27. https://doi.org/10.1177/0038040717741180

Pallarés, M., Ahedo, J., y Planella, J. (2017). Ciudad Educadora, desde la relación: Educación, integración, ciudad y comunicación. Kultur, 4(8), 327-354. http://doi.org/10.6035/Kultur.2017.4.8.13 
PEDRO MOISÉS ARAMENDI JÁUREGUI, ITZIAR REKALDE-RODRÍGUEZ, Y ESTHER CRUZ IGLESIAS LAS CIUDADES EDUCADORAS ANTE LA SEGREGACIÓN ESCOLAR: CAMINANDO HACIA EL DESARROLLO SOSTENIBLE

Pàmies, J. (2013). El impacto de los agrupamientos escolares. Los espacios de aprendizaje y sociabilidad de los jóvenes de origen marroquí en Barcelona. Revista de Educación, 362, 133-158.

Rodríguez, G., Gil, J., y García, E. (1999). Metodología de la investigación cualitativa. Aljibe.

Rosiek, J. (2019). School segregation: A realist's view. Phi Delta Kappan, 100(5), 8-13. https:// doi.org/10.1177/0031721719827536

Rossetti, M. (2014). La segregación escolar como un elemento clave en la reproducción de la desigualdad. Naciones Unidas-Cepal.

Rubia, F. A. (2013). La segregación escolar en nuestro sistema educativo. Forum Aragón, $10,47-52$.

Sindic de Greuges de Catalunya (2016). La segregaciín escolar en Catalunya (I): la gestión del proceso de admisión del alumnado. Sindic de Greuges de Catalunya.

Sleeter, C. (2018). La transformación del currículo en una sociedad diversa: ¿quién y cómo se decide el currículum? RELIEVE, 24(2), 1-12. https://doi.org/10.7203/relieve.24.2.13374

Taylor, S. J., y Bogdan, R. (1994). Introducción a los métodos cualitativos de investigación. La búsqueda de significados. Paidós.

Valiente, O. (2008). ¿A qué juega la concertada? La segregación escolar del alumnado inmigrante en Cataluña (2001-06). Profesorado. Revista de Curriculum y formación del Profesorado, 12(2), 1-23.

Vila, F. (2018). Políticas educativas del consorcio de educación de Barcelona en relación al aprendizaje-servicio como innovación social. Ridas, Revista Iberoamericana de Aprendizaje Servicio, 6, 33-41. 